\title{
Article \\ TDP-43 Pathology and Prionic Behavior in Human Cellular Models of Alzheimer's Disease Patients
}

\author{
Eva P. Cuevas ${ }^{1,2} \mathbb{D}$, Alberto Rodríguez-Fernández ${ }^{1}\left(\mathbb{D}\right.$, Valle Palomo ${ }^{1,2}\left(\mathbb{D}\right.$, Ana Martínez ${ }^{1,2, *(\mathbb{D})}$ \\ and Ángeles Martín-Requero $2,3, * \mathbb{D}$
}

1 Department of Structural and Chemical Biology, Centro de Investigaciones Biológicas, Margarita Salas (CSIC), Ramiro de Maeztu 9, 28040 Madrid, Spain; e.p.cuevas@csic.es (E.P.C.); alberto.rodriguezf@edu.uah.es (A.R.-F.); vpalomo@cib.csic.es (V.P.)

2 Centro de Investigación Biomédica en Red de Enfermedades Neurodegenerativas (CIBERNED), Instituto de Salud Carlos III, 28031 Madrid, Spain

3 Department of Molecular Biomedicine, Centro de Investigaciones Biológicas, Margarita Salas (CSIC), Ramiro de Maeztu 9, 28040 Madrid, Spain

* Correspondence: ana.martinez@csic.es (A.M.); amrequero@cib.csic.es (Á.M.-R.)

check for updates

Citation: Cuevas, E.P.; RodríguezFernández, A.; Palomo, V.; Martínez, A.; Martín-Requero, Á. TDP-43 Pathology and Prionic Behavior in Human Cellular Models of Alzheimer's Disease Patients. Biomedicines 2022, 10, 385. https://doi.org/10.3390/ biomedicines 10020385

Academic Editor: Kuen-Jer Tsai

Received: 17 January 2022

Accepted: 31 January 2022

Published: 5 February 2022

Publisher's Note: MDPI stays neutral with regard to jurisdictional claims in published maps and institutional affiliations.

Copyright: (C) 2022 by the authors. Licensee MDPI, Basel, Switzerland. This article is an open access article distributed under the terms and conditions of the Creative Commons Attribution (CC BY) license (https:// creativecommons.org/licenses/by/ $4.0 /)$.

\begin{abstract}
Alzheimer's disease (AD) is a neurodegenerative disorder for which there is currently no effective treatment. Despite advances in the molecular pathology of the characteristic histopathological markers of the disease (tau protein and $\beta$-amyloid), their translation to the clinic has not provided the expected results. Increasing evidences have demonstrated the presence of aggregates of TDP-43 (TAR DNA binding protein 43) in the postmortem brains of patients diagnosed with AD. The present research is focused on of the study of the pathological role of TDP-43 in AD. For this purpose, immortalized lymphocytes samples from patients diagnosed with different severity of sporadic AD were used and the TDP-43 pathology was analyzed against controls, looking for differences in their fragmentation, phosphorylation and cellular location using Western blot and immunocytochemical techniques. The results revealed an increase in TDP-43 fragmentation, as well as increased phosphorylation and aberrant localization of TDP-43 in the cytosolic compartment of lymphocytes of patients diagnosed with severe AD. Moreover, a fragment of approximately $25 \mathrm{KD}$ was found in the extracellular medium of cells derived from severe AD individuals that seem to have prion-like characteristics. We conclude that TDP-43 plays a key role in AD pathogenesis and its cell to cell propagation.
\end{abstract}

Keywords: Alzheimer's disease; extracellular vesicles; immortalized lymphocytes; vesicles; prionic behavior; TDP-43

\section{Introduction}

Alzheimer's Disease (AD) is a neurodegenerative disorder marked by progressive impairment of cognitive ability, generally in later life, affecting more than 50 million people worldwide [1]. Age is the strongest risk factor for AD [2]. The prevalence of AD increased from $10 \%$ in individuals over 65 to $40 \%$ in subject over 80 years old [3], and it is expected to triple by 2050 due to an ageing population [4].

The disease begins with a decline in cognition followed by a number of other changes in brain functioning, including impairments in language and visual-spatial skills, and disorientation. This impairment in cognitive functions is due to anatomical atrophy of AD brains, which correlates with severe neuronal loss [5]. In particular, the lack of good coordination within structures like prefrontal cortex, hippocampus and amygdala seems to play a predominant role in cognitive deficits in the advanced age [6].

Based on age of onset, $\mathrm{AD}$ can be divided into early onset $\mathrm{AD}$, and the more common, late-onset AD, in people over 65 years old, accounting for more than $90 \%$ of all AD cases [7]. Most cases of early onset AD have familial history of AD and are carriers of dominant 
autosomal mutations in three genes, amyloid precursor protein (APP), presenilin-1 (PSEN-1), presenilin-2 (PSEN-2) [8]. On the other hand, late onset AD is considered sporadic, although genetic risk factors have been identified [9].

$\mathrm{AD}$ is considered a multifactorial disease associated with a number of risk factors other than advanced age and genetic factors, such as environmental factors, diet, cardiovascular diseases, and diabetes, head injuries, and obesity among others [10-12]. Recently, the insulin resistance within the brain, the so-called type 3 diabetes (T3DM) has been shown to have a big impact in neurocognition in $\mathrm{AD}$ [13].

AD is characterized by two main neuropathological hallmarks: extracellular amyloid- $\beta$ (A $\beta)$ deposition in senile plaques and intracellular accumulations of hyperphosphorylated microtubule-associated tau, called neurofibrillary tangles (NFT) [14-16].

Based in the density of NFTs in various brain regions, AD cases have been classified in three different subtypes hippocampal-sparing, with lower NFT in hippocampus, limbicpredominant with lower cortical NFT, and the more frequent typical AD forms [17]. In addition to senile plaques and NFT, transactive response DNA-binding protein (TDP-43) has been found in limbic brain regions in up to $70 \%$ of late-onset AD patients [18,19]. Interestingly, TDP-43-positive inclusions in limbic brain regions have been recently considered as limbic-predominant age-associated TDP-43 encephalopathy (LATE) [20], suggesting that late-onset AD patients with TDP-43 proteinopathy may display concomitant LATE neurological changes.

TDP-43 was originally found to associate with frontal temporal lobar degeneration with ubiquitin inclusions (FTLD-U) and amyotrophic lateral sclerosis (ALS) [21]. These neurodegenerative diseases show a partial overlap in their clinical presentation, genetics and pathology [22] suggesting that they are part of a disease spectrum [23]. While FTD refers to a number of disorders with distinctive clinical phenotype caused by the loss of cortical neurons and basal ganglia, inducing changes in personality and language deficit [24]. ALS is characterized by the progressive loss of motoneurons, weakness of innervated muscles, and death by respiratory failure [25]. TDP-43 proteinopathy is the hallmark for the FTD/ALS spectrum. In addition, it is now recognized that TDP-43 pathology is present in other neurological diseases including AD and even in non-demented individuals [26,27].

The manner in which TDP-43 pathology induces neuron degeneration is not yet completely understood, and the role of TDP-43 in cognition remains elusive, since conflicting results had been reported [28,29]. Apparently TDP-43 pathology is most common in the medial temporal lobe, which may account for its robust association with episodic memory dysfunction [30].

TDP-43 is a predominantly nuclear protein, although it can shuttle between the nucleus and cytosol. It plays a variety of roles in RNA metabolism, including transcription, splicing, mRNA transport, mRNA stability through recruitment into stress granules (SGs), and microRNA biosynthesis [31,32]. Under pathological conditions, TDP-43 undergoes a number of posttranslational modifications (PTMs), including phosphorylation at serines 403/404 and 409/410, ubiquitination and abnormal cleavage to generate C-terminal fragments (CTFs). These posttranslational modifications lead to cytoplasmic accumulation and aggregation of TDP-43 [33]. A gain of toxic function in the cytoplasm as well as a loss of nuclear function seem to constitute TDP-43 disease mechanisms [34,35]. While TDP-43 pathological features of ALS and FTLD-TDP appear to be well established, the pattern of PTMs of TDP-43 in AD cases, as well as dissemination of TDP-43 proteinopathy remains to be fully elucidated.

The present work was undertaken to better understand the role and significance of TDP-43 in AD. To accomplish this goal, we assessed and compared pathological characteristics of TDP-43 of control and AD-derived immortalized lymphocytes. These lymphoblastoid cells lines had been extensively characterized in our laboratory, demonstrating that they display disease specific signature molecules [36-38], and therefore considered suitable experimental models for mechanistic and therapeutic studies. Moreover, we have 
recently demonstrated, specifically, the usefulness of lymphoblastoid cell lines to study TDP-43 homeostasis in FTLD-TDP or ALS [39-41].

The results presented here indicate an increase in TDP-43 fragmentation, as well as increased phosphorylation and aberrant localization of TDP-43 in the cytosolic compartment of lymphoblasts of patients diagnosed with severe AD. Moreover, a fragment of approximately $25 \mathrm{KDa}$ was found in the extracellular medium of cells derived from AD individuals, that appears to be transported by extracellular vesicles (EVs) inducing TDP-43 pathological features and cytoskeletal changes in control cells. The data may suggest a role of these EVs containing fragmented TDP-43 in contributing to the propagation of AD disease in a prion-like manner.

\section{Materials and Methods}

\subsection{Materials}

RPMI 1640 culture medium (Cat\#21875034 Gibco/Thermo Fisher, Waltham, MA, USA), DMEM culture medium (Cat\#41965039 Gibco/Thermo Fisher, Waltham, MA, USA), Fetal Bovine Serum (FBS) (Cat\#: F7524, Merck, Madrid, Spain), penicillin/ streptomycin (Cat\#15140-122, Gibco/Thermo Fisher Waltham, MA, USA), polyvinylidene difluoride (PVDF) membranes for Western blots (Bio-Rad, Alcobendas, Madrid, Spain), enhanced chemiluminescence (ECL) system (Amersham, Uppsala, Sweden), Pierce BCA Protein Assay kit (Thermo Fisher, Waltham, MA, USA), protease inhibitor complete mini mixture (Roche, Mannheim, Germany).

Antibodies used in this study were from Santa Cruz Biotechnologies (Santa Cruz, CA, USA), Cell Signal (Danvers, MA, USA), Thermo Fisher (Waltham, MA, USA), Molecular Probes (Thermo Fisher), Bio-Rad (Alcobendas, Madrid, Spain) or Proteintech, (Manchester, UK) and are listed in Table 1.

Table 1. Primary and secondary antibodies used in the analysis.

\begin{tabular}{|c|c|c|c|}
\hline Primary Antibody & Species & $\begin{array}{l}\text { Dilution } \\
\text { (WB/IF) }\end{array}$ & Supplier (Catalog\#) \\
\hline TDP-43 & Rabbit & $1: 1000 /$ na & $\begin{array}{l}\text { Proteintech } \\
(10782-2-A P)\end{array}$ \\
\hline TDP-43 & Mouse & 1:1000/1:1000 & $\begin{array}{l}\text { Proteintech } \\
\text { (67345-1-Ig) }\end{array}$ \\
\hline $\begin{array}{l}\mathrm{p}(\text { Ser } 409 / 410)- \\
\text { TDP-43 }\end{array}$ & Rabbit & 1:500/1:1000 & $\begin{array}{l}\text { Proteintech } \\
\text { (22309-1-AP) }\end{array}$ \\
\hline$\alpha$-tubulin & Mouse & $1: 5000 /$ na & Santa Cruz (23948) \\
\hline GADPH & Rabbit & $1: 1000 /$ na & Cell Signal (5174) \\
\hline Flotillin-1 & Rabbit & $1: 1000 /$ na & $\begin{array}{l}\text { Thermo Fisher } \\
\text { (PA5-97756) }\end{array}$ \\
\hline Secondary Antibody & $\begin{array}{l}\text { Immunological } \\
\text { Procedure }\end{array}$ & Dilution & Supplier (Catalog\#) \\
\hline $\begin{array}{l}\text { Goat anti-mouseIgG } \\
\text { HRP conjugate }\end{array}$ & WB & $1: 7000$ & Bio-Rad (1706516) \\
\hline $\begin{array}{l}\text { Goat anti-rabbitIgG } \\
\text { HRP conjugate }\end{array}$ & WB & $1: 7000$ & Bio-Rad (1706515) \\
\hline Anti-mouse Alexa 488 & IF & $1: 1000$ & $\begin{array}{l}\text { Molecular Probes } \\
\text { (A-11001) }\end{array}$ \\
\hline
\end{tabular}

na: not apply; WB: Western blot; IF: immunofluorescence.

\subsection{Subjects}

Healthy controls and patients were recruited from Hospital Doce de Octubre, Madrid Spain. The clinical diagnosis of probable AD was based on the criteria of the National Institute of Neurological and Communicative Disorders and Stroke and the Alzheimer's Disease and Related Disorders Association (NINCDS-ADRDA) [42], and diagnosis required evidence of cognitive decline (neuropsychological test battery, clinical mental examination) 
as well as evidence of impairment in social or occupational function. The Mini-Mental State Examination was used to assess cognitive function [43]. Classification of mild, moderate and severe degrees of AD was performed using DSM-III-R criteria. Control individuals were usually age-matched family members of the patients, with no signs of neurological disease or cognitive decline. Demographic and clinical characteristics of subjects are provided in Table 2. This study was approved by the Ethic Committee of Clinical Investigation of the Hospital '12 de Octubre'(CEIC02506) and by the Spanish Council of Higher Research Institutional Review Board (15 March 2007) Informed consent from all subjects was obtained prior to their participation.

Table 2. Summary data of the study population.

\begin{tabular}{cccccc}
\hline Cell Lines & $\mathbf{n}$ & \multicolumn{2}{c}{ Age } & \multicolumn{2}{c}{ Gender } \\
\hline & & Mean & Range Age & Male & Female \\
\hline CONTROL & 8 & $68 \pm 12$ & $52-83$ & 5 & 3 \\
AD & & & & 6 & 6 \\
Total & 12 & $74 \pm 7$ & $60-84$ & 2 & 2 \\
Mild & 4 & $74 \pm 6$ & $66-80$ & 2 & 2 \\
Moderate & 4 & $79 \pm 5$ & $73-84$ & 2 & 2 \\
Severe & 4 & $70 \pm 7$ & $60-75$ & & \\
\hline
\end{tabular}

Values expressed as mean \pm standard deviation. Healthy control individuals, no sign of neurological disease; AD Patients with a diagnosis of probable Alzheimer's disease; mild AD (DSM-III-R, Mini Mental State Examination (MMSE) score between 18-24, moderate AD (MMSE: 10-18), and severe AD (MMSE: <10).

\subsection{Isolation of Peripheral Blood Mononuclear Cells and Establishment of Lymphoblastoid Cell Lines}

Blood samples (approximately $8 \mathrm{~mL}$ ) were obtained through antecubital vein puncture in EDTA-treated tubes. Peripheral blood mononuclear cells (PBMCs) were isolated on Lymphoprep ${ }^{\mathrm{TM}}$ density-gradient centrifugation according to the instructions of the manufacturer (Axix-Shield Po CAS, Oslo, Norway).

Establishment of lymphoblastoid cell lines (LCLs) was performed in our laboratory, by infecting peripheral blood lymphocytes with the Epstein Barr virus (EBV) [44].

\subsection{Cell Culture}

Lymphoblastoid cells were grown in suspension in T flasks in an upright position, in approximately $10 \mathrm{~mL}$ RPMI 1640 medium that contained 10\% (v/v) fetal bovine serum (FBS), and 1\% penicillin/ streptomycin. U2OS cells were obtained from the American Type Culture Collection and grown in DMEM media, supplemented with $10 \%(v / v)$ fetal bovine serum and $1 \%$ penicillin/streptomycin. All cell lines were grown at $37^{\circ} \mathrm{C}$ in a humidified $5 \% \mathrm{CO}_{2}$ atmosphere.

\subsection{Analysis of mRNA Levels by Quantitative Real-Time PCR}

Total RNA extraction, cDNA synthesis and quantitative polymerase chain reaction (PCR) was done as detailed in the previous article [18]. Quantitative real-time PCR was performed with LightCycler ${ }^{\circledR} 96$ System (Roche, Mannheim, Germany) and the associated software using the manufacturer's recommended conditions. Each reaction was performed in biological triplicates with $20 \mathrm{ng}$ of cDNA by using FastStart Essential DNA Green Master (Roche, Mannheim, Germany). The sequences of the forward and reverse primers used are the following: for hTDP-43 FW: 5'-GAGAAGTTCTTATGGTGCAG-3' and RV: 5'-TGGCTTTGCTTAGAATTAGG-3' , for hRPS17 FW: 5' -CCATTATCCCCAGCAAAAAG-3' and RV: 5'-GAGACCTCAGGA ACATAATTG-3'. Data analysis was based on the $\Delta \triangle \mathrm{CT}$ method with normalization of the raw data to hRPS17 housekeeping gene. 


\subsection{Inmunological Assays}

\subsubsection{Cell Extracts}

To prepare whole cell extracts the lymphoblasts were seeded at initial density of $1 \times 10^{6}$ cells $\times \mathrm{mL}^{-1}$ and $24 \mathrm{~h}$ later, cells were harvested, washed in PBS and then lysed in ice-cold RIPA lysis buffer (50 mM Tris- $\mathrm{HCl}$ (pH 7.4), $150 \mathrm{mM} \mathrm{NaCl,} 5 \mathrm{mM}$ EDTA, $15 \mathrm{mM}$ $\mathrm{MgCl}_{2}, 0.5 \%$ (vol/vol) sodium deoxycholate, $0.5 \%$ (vol/vol) NP-40 and $0.1 \%$ (vol/vol) SDS), containing $1 \mathrm{mM}$ sodium orthovanadate, $1 \mathrm{mM}$ phenylmethylsulfonylfluride (PMSF), $1 \mathrm{mM}$ sodium pyrophosphate and protease inhibitor mixture. The protein content of the extracts was determined by de Pierce BCA Protein Assay kit.

\subsubsection{Western Blot Analysis}

$50-\mu \mathrm{g}$ of protein from cell extracts or $35 \mu \mathrm{L}$ of extracellular medium were fractionated on an SDS polyacrylamide gel, transferred to PVDF membrane and blocked with $5 \%$ non-fat milk. The antibodies used are listed in Table 1 . Bands were detected with a chemiluminescent substrate detection system ECL using the Chemidoc Imaging System (Bio-Rad, Alcobendas, Madrid, Spain). Protein band densities were quantified using Image J software (National Institutes of Health, Bethesda, MD, USA).

\subsubsection{Confocal Laser Scanning Microscopy}

Immunofluorescence analysis was performed on cells grown on coverslips. For the attachment of lymphoblastoid cells, the coverslips were previously coated with a solution of $0.025 \%$ Gelatin (Sigma, Madrid, Spain) for $30 \mathrm{~min}$ at room temperature followed by a solution of $1 \mathrm{mg} / \mathrm{mL}$ poly-L-lysine (Sigma, Madrid, Spain) diluted 1:50 in Borax buffer $\left(\mathrm{Na}_{2} \mathrm{~B}_{4} \mathrm{O}_{7} \cdot 10 \mathrm{H}_{2} \mathrm{O} 15 \mathrm{mM}, \mathrm{pH} 8.4\right)$ overnight at $37^{\circ} \mathrm{C}$.

Cells were fixed with $4 \%$ paraformaldehyde for $25 \mathrm{~min}$, permeabilized with $0.1 \%$ TritonX100 for $10 \mathrm{~min}$ and then blocked for $1 \mathrm{~h}$ at $37{ }^{\circ} \mathrm{C}$ with PBS-BSA $1 \%$. Cells were incubated at $37^{\circ} \mathrm{C}$ in a humidified chamber with the primary and secondary antibodies described in Table 1. Alexa Fluor-568 Phalloidin (1:1000, Molecular Probes, Waltham, MA, USA) was used for F-actin stain and nuclear staining was performed by incubation with DAPI (1:1000, Sigma). The preparations were mounted with Fluor Save reagent (Calbiochem, Madrid, Spain). Confocal microscopy analyses were performed using Leica TCS SP5 and a $\times 63$ or $\times 100$ oil immersion objective. Images were analysed using Leica Application Suite $X$ (version 3.5.7.23225) and Image J software (version 1.53K).

\subsection{Conditioned Medium Experiments}

Conditioned medium from AD lymphoblastoid cells was collected after 72-96 h and centrifuged to eliminate cells and debris. Control lymphoblastoid cell lines or U2OS cells were cultured in the conditioned medium plus fresh medium in a 3:1 ratio for $72 \mathrm{~h}$.

\subsection{Extracellular Vesicles Isolation and Characterization}

To generate conditioned medium for extracellular vesicles isolation, lymphoblasts were grown in RPMI medium with 10\% of exosome-depleted FBS (Gibco, Waltham, MA, USA), instead of normal FBS. After $72 \mathrm{~h}$, conditioned medium was recollected by centrifugation at $2000 \times g$ for $30 \mathrm{~min}$ to remove cells and debris. EVs were prepared with Total Exosome Isolation reagent (Invitrogen) following manufacturers' recommendations. EV-containing pellet was resuspended in phosphate-buffered saline and stored at $-20^{\circ} \mathrm{C}$ until further analyses.

EV characterization was performed by nanoparticle tracking analysis (NTA) and Western Blot. Size distribution and quantification of EVs preparations were analyzed by measuring the rate of Brownian motion with a NanoSight LM10 system with a $630 \mathrm{~nm}$ laser (NanoSight, Wiltshire, UK), equipped with fast video capture and particle-tracking software. EVs samples were diluted 1:1000 in Hank's balanced salt solution (HBSS), disaggregated and injected in the sample cubicle of the NanoSight. The mean of the number of particles acquired per milliliter was compared between AD and control cells and the measurements of EVs concentration (particles $/ \mathrm{mL}$ ) were normalized with the cell number from which 
conditioned medium containing EVs was recollected. For Western Blot analysis $20 \mu \mathrm{L}$ of EVs were lysed with Laemmli buffer and denaturalized at $95{ }^{\circ} \mathrm{C}$ for $5 \mathrm{~min}$. Western Blots were performed in parallel in EVs samples and cell lysates and the antibodies used are described in Table 1.

\subsection{Statistical Analysis}

Statistical analyses were performed using Graph Pad Prism software version 6 (La Jolla, CA, USA). Data are presented as means \pm standard deviation (SD) of the mean. Statistical significance was estimated using one-way ANOVA followed by the Bonferroni test for multiple comparations, or, two-tailed Student's $t$-test for statistical comparisons between groups. A " $p$-value $<0.05$ " was considered statistically significant.

\section{Results}

\subsection{TDP-43 Pathology in AD Lymphoblasts}

To examine TDP-43 pathology in human lymphoblasts, we first analyzed the expression of TDP-43 mRNA and protein levels in immortalized lymphocytes from AD patients as a function of disease severity. Figure 1A shows an increase in TDP-43 mRNA levels in AD lymphoblasts and a trend to elevated protein levels in severe AD cases as compared with control individuals (Figure 1B).

Interestingly, a longer exposure of TDP-43 blots revealed the presence of a TDP-43 fragment of approximately 25-30 KDa perhaps due to TDP-43 cleavage, in most of the AD cases but not in control samples (Figure 1B).

We then, analyzed the phosphorylation status of TDP-43 in control an AD (mild, moderate, and severe) patients, using a phospho-specific antibody by Western blotting and confocal laser microscopy. As shown in Figure 2A a trend to an increase in phosphorylated levels of full length and truncated ( $25 \mathrm{KDa}$ ) TDP-43 was observed in AD lymphoblasts, regardless of $A D$ severity, reaching statistical significance in moderate and severe AD cases. Figure 2B shows a significant increase in phosphorylated levels of TDP-43 protein, as assessed by immunofluorescence in lymphoblasts derived from severe AD patients.

Increased phosphorylation of TDP-43 had been associated with mislocalization of the protein in TDP-43 proteinopathies such as ALS and FTD [5]. For this reason, we seek to investigate whether nucleo-cytoplasmic TDP-43 shuttling is also perturbed in AD lymphoblasts. To this end we analysed the subcellular TDP-43 by immunofluorescence and laser confocal microscopy. As shown in Figure 3A, TDP-43 is mainly expressed in the nucleus of controls, as expected, whereas lymphoblasts from AD patients display a significant accumulation of TDP-43 in the cytosolic compartment and a significative reduction in the nucleo-cytoplasmic ratio (Figure 3B).

Moreover, immunofluorescence staining for filamentous actin (F-actin) with Alexa Fluor-568 phalloidin, revealed cytoskeletal abnormalities in AD lymphoblasts (Figure 3A) such as the increased formation of actin protrusions reminiscent of tunneling nanotubes (TNTs) or TNT-like structures. The percentage of AD cells showing these structures is significantly higher than in the case of control cells and seems to increase even more in severe AD cases (Figure 3C). We can observe also co-localization of F-actin and TDP-43 in the cytosolic compartment of AD cells and TDP-43 aggregates were found inside these tubular actin channels (Figure 3A, bottom zoom). 
A)

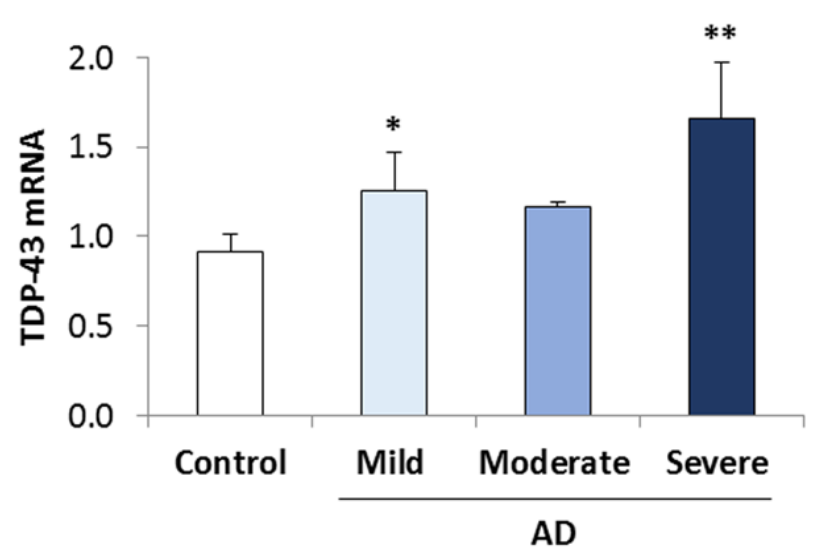

B)
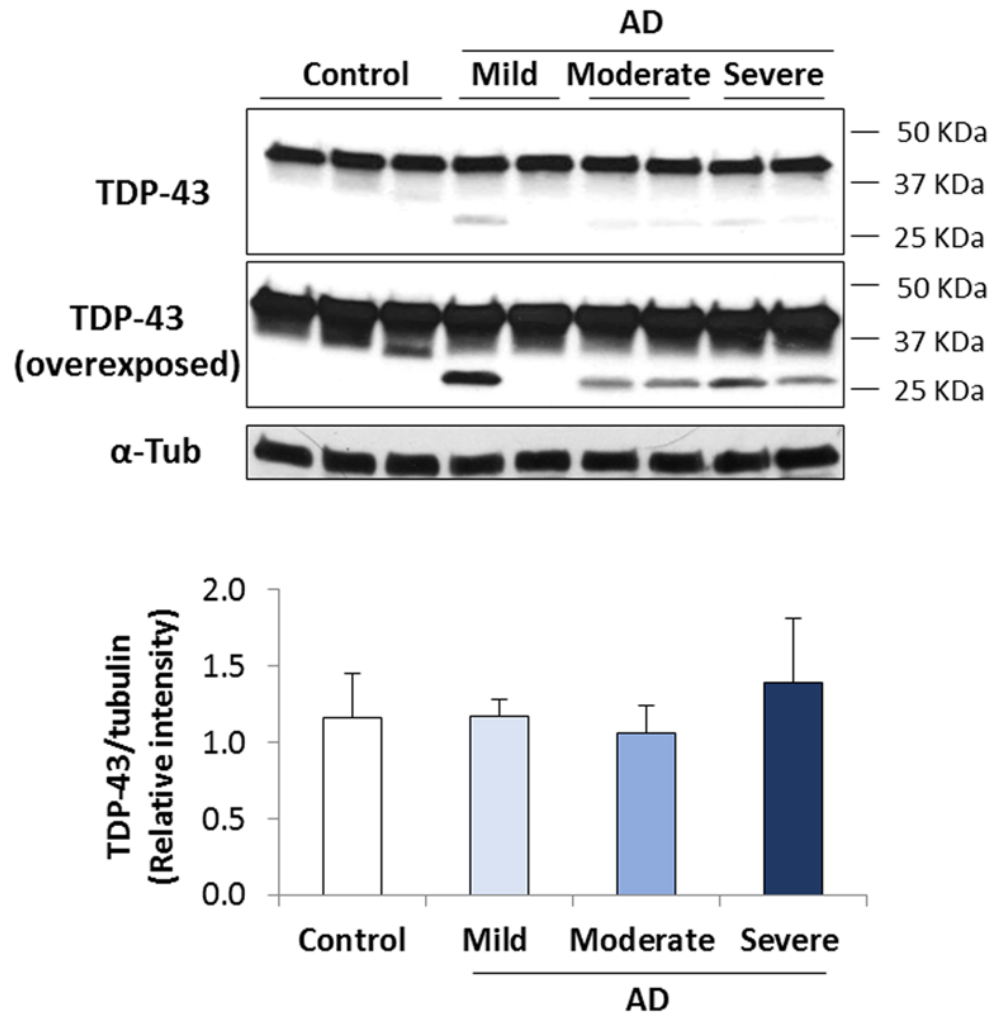

Figure 1. TDP-43 mRNA and protein expression levels in control and AD lymphoblasts. Immortalized lymphocytes from control and AD subjects (mild, moderate or severe patients), were seeded at an initial density of $1 \times 10^{6} \mathrm{~mL}^{-1}$ and cultured in RPMI medium containing $10 \%$ FBS. $24 \mathrm{~h}$ later cells were harvested to isolate RNA and to prepare cell lysates. (A) TDP-43 mRNA expression levels were analyzed by quantitative RT-PCR. RPS17 levels serve as internal control. Results represent the mean \pm standard deviation (SD) of two independent experiments performed on triplicate with four patients of each group. Statistical analysis was performed using 1-way analysis of variance (ANOVA; mRNA TDP-43: $\mathrm{F}_{3.11}=8.733$ ). ${ }^{*} p<0.05,{ }^{* *} p<0.01$ significantly different from control cells. (B) Western blot analyses (upper panels) and densitometric quantification (lower panel) were performed for the expression of TDP-43 protein. $\alpha$-tubulin was used as loading control. A representative blot is shown and bars are the mean $\pm \mathrm{SD}$ for each experimental group of two independent experiments. 
A)
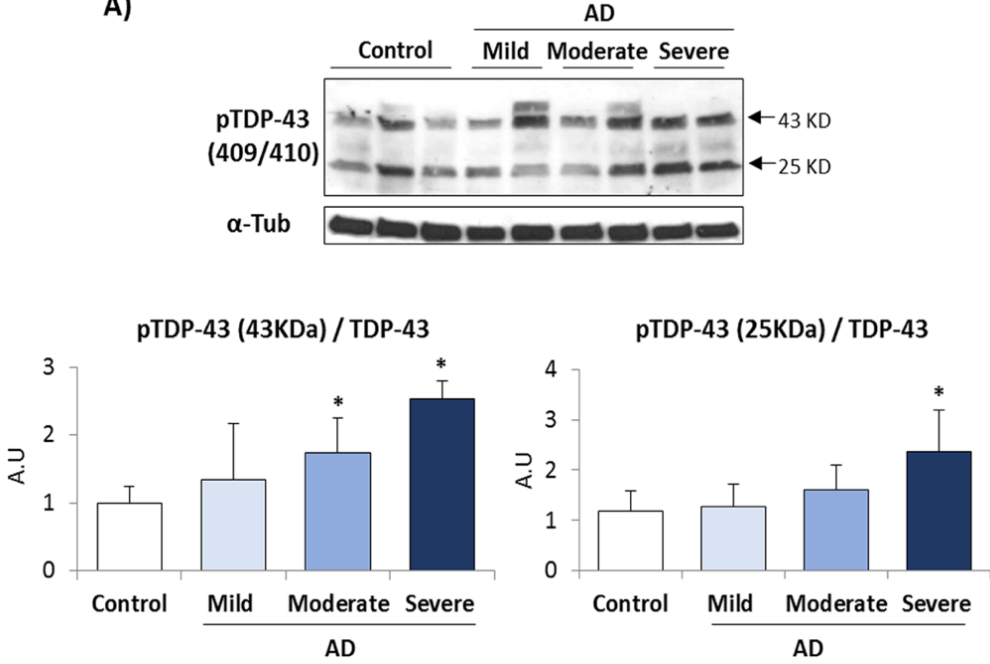

B)
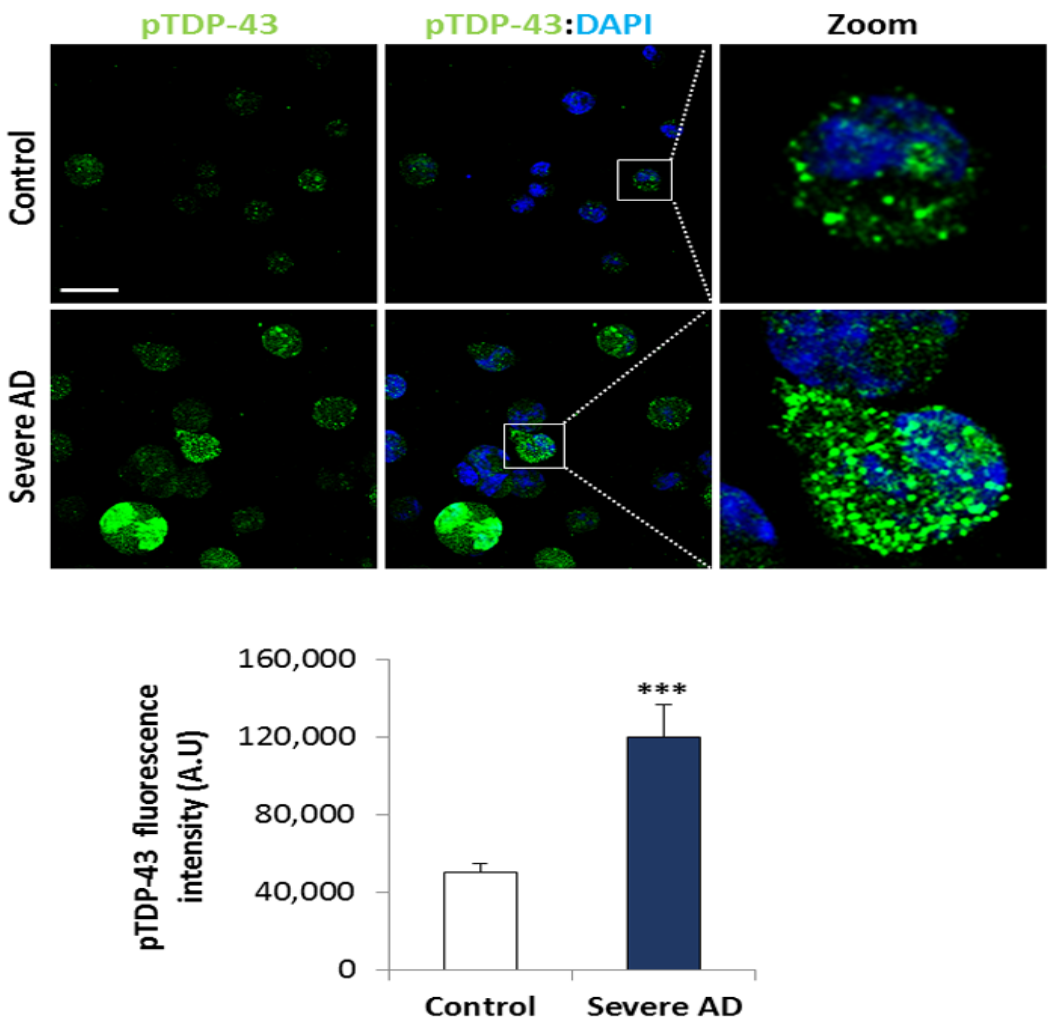

Figure 2. TDP-43 phosphorylation is increased in AD lymphoblasts. Immortalized lymphocytes from control and AD subjects (mild, moderate or severe patients) were incubated as described in legend of Figure 1, (A) Representative Western blot analysis of AD and control samples with pTDP43 (Ser409/410) antibody. $\alpha$-tubulin was used as loading control. Densitometric quantification of pTDP43 was normalized with total TDP-43 levels. Bars are the mean \pm SD for each experimental group of two independent experiments. Statistical analysis was performed using 1-way analysis of variance (ANOVA; pTDP-43 (43KDa): $\mathrm{F}_{3.11}=5.356$, pTDP-43 (25KDa): $\left.\mathrm{F}_{3.10}=3.842\right) .\left({ }^{*} p<0.05\right)$. (B) Immunofluorescence staining of pTDP-43 (green) in control or severe AD lymphoblasts. Nuclei were counterstained with DAPI (blue). Scale bar, $20 \mu \mathrm{m}$. Fluorescence intensity quantification was performed using Image J software in at least 4 fields of view (A.U, arbitrary units). Bars are the mean \pm SD of two independent experiments. Statistical analysis was performed using the Student $t$ test $\left.{ }^{* * *} p<0.001\right)$. 
A)

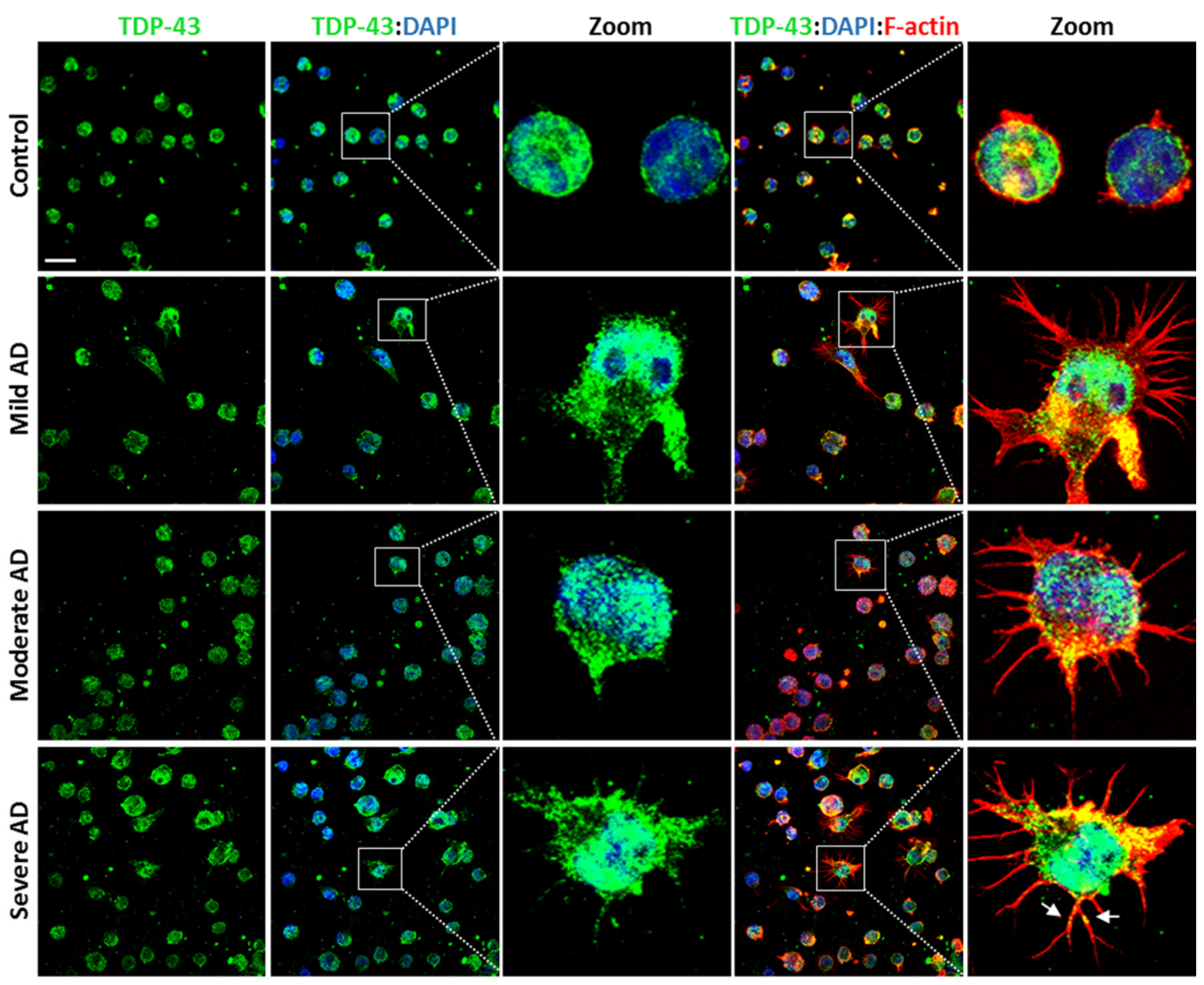

B)

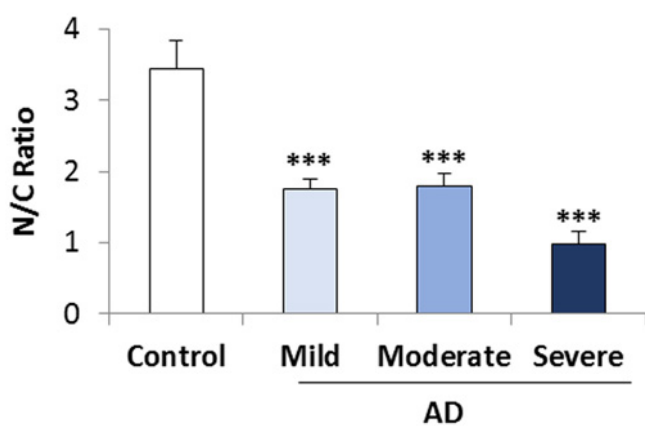

C)

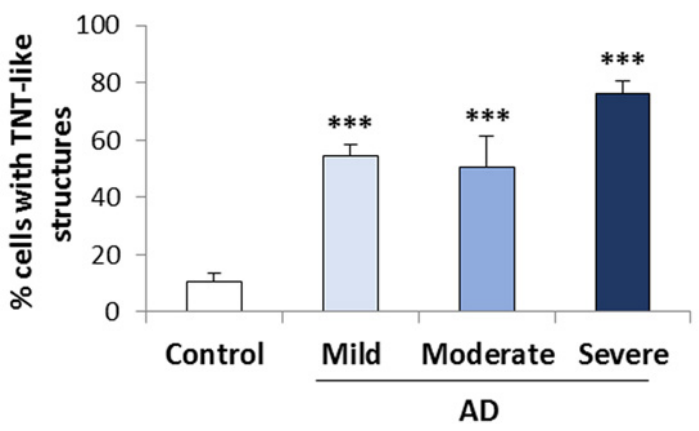

Figure 3. Lymphoblasts of AD patients display significative changes in TDP-43 subcellular localization and actin cytoskeleton organization. Lymphoblasts were seeded at $10^{6}$ cells $\times \mathrm{mL}^{-1}$ and incubated in RPMI containing 10\% FBS for $24 \mathrm{~h}$. (A) Confocal immunofluorescence images of TDP-43 (green), F-actin (red) and DAPI staining (blue) in the indicated cells. Scale bar, $20 \mu \mathrm{m}$. (B) Fluorescence quantification and region of interest (ROI) selection was performed using Image J software. Nucleo-cytoplasm ratio was calculated using mean nuclear intensity divided by the mean cytoplasmic intensity. Measures were performed cell to cell in at least 4 fields of view. (C) The\% of cells with F-actin protrusions (TNT-like structures) was measured in at least 4 fields of view. Bars are the mean $\pm \mathrm{SD}$ of two independent experiments with at least two different patients of each type (control, mild AD, moderate AD, severe AD). Statistical analysis was performed using 1-way analysis of variance (ANOVA; N/C Ratio: $\mathrm{F}_{3.10}=71.17 \%$ TNTs: $\left.\mathrm{F}_{3.10}=107.7\right)$. $\left({ }^{* * *} p<0.001\right.$ ). 


\subsection{Conditional Medium from AD Lymphoblast Is Enriched in TDP-43 Fragments}

It has been documented that full-length and fragmented TDP-43 may be released in extracellular vesicles or exosomes in different neurological diseases. For this reason, we first preformed Western blot analysis looking for TDP-43 protein in the extracellular medium of control and AD lymphoblasts. Figure $4 \mathrm{~A}$ shows a representative immunoblot carried out in the conditioned medium from control and AD lymphoblasts, where we can observe a TDP-43 fragment of approximately 25-30 KDa that appears in most AD cases, regarding of disease severity, and not in control lymphoblasts. Figure 4B shows the percentage of samples with this TDP-43 fragment in a total of 8 healthy individuals, and $12 \mathrm{AD}$ patients ( 4 mild, 4 moderate and 4 severe). Of note a band of approximately $35 \mathrm{KDa}$ was found in one control subject. We next performed conditioned medium (CM) experiments to investigate the possible transmission of TDP-43 pathology. CM from AD severe cases was collected after 72-96 h of culture and added to lymphoblasts derived from control individuals for $72 \mathrm{~h}$. Immunofluorescence staining with anti-pTDP-43, revealed a significant increase in TDP-43 phosphorylation in control cells incubated with CM from AD cells (Figure 5A). Moreover, cytosolic TDP-43 accumulation, with a significative reduction in the nucleo-cytoplasmic ratio, was observed in control cells growing in CM of AD cells, when subcellular localization of TDP-43 was analyzed by immunostaining with anti-TDP43 and DAPI (Figure 5B). We can also observe that in the control cells maintained in the $\mathrm{CM}$ of AD cells appear similar TNT-like structures (Figure $5 \mathrm{~B}$, right panels) to the ones previously found in AD lymphoblasts (Figure 3A, right panels).

A)

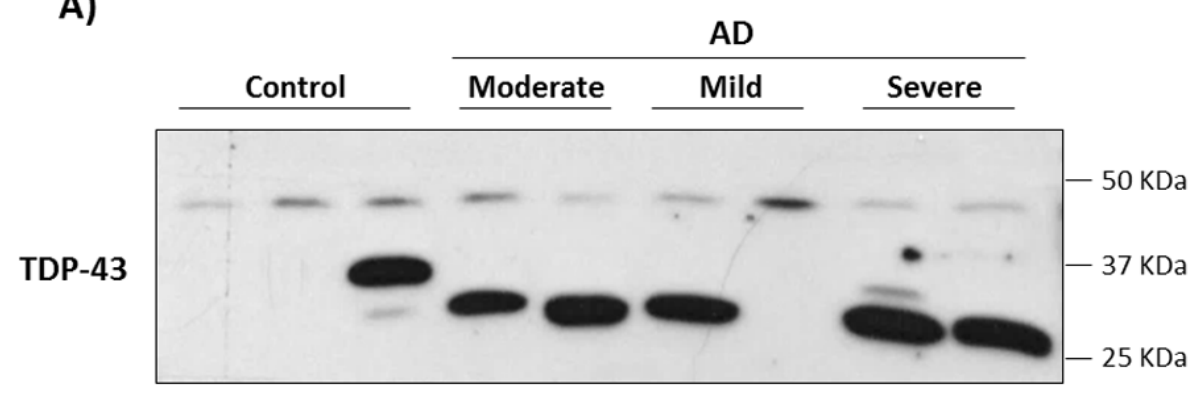

B)

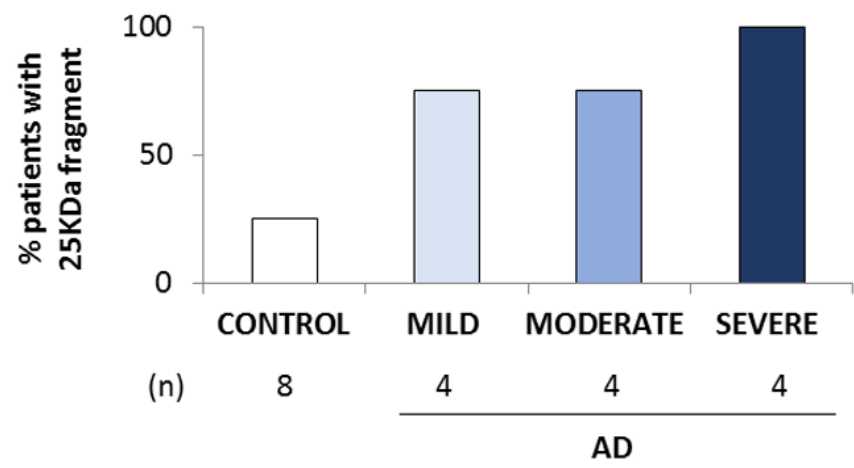

Figure 4. A $25 \mathrm{KDa}$ fragment of TDP-43 is detected in the extracellular medium of AD lymphoblasts. (A) Representative Western blot of extracellular TDP-43 in the extracellular medium from control and AD lymphoblasts (mild, moderate and severe AD cases). (B) The \% of samples with presence of $25 \mathrm{KDa}-\mathrm{TDP}-43$ extracellular fragment was calculated in a total of 8 controls and 4 AD lymphoblasts of each type (moderate $\mathrm{AD}$, mild $\mathrm{AD}$, severe $\mathrm{AD}$ ). 
A)
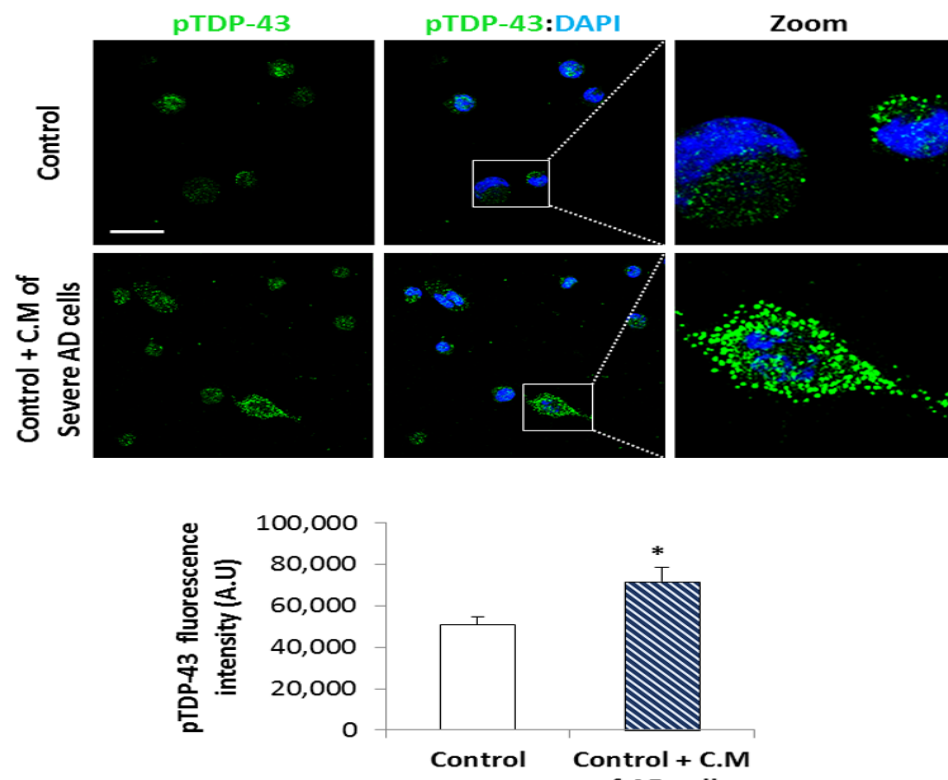

B)
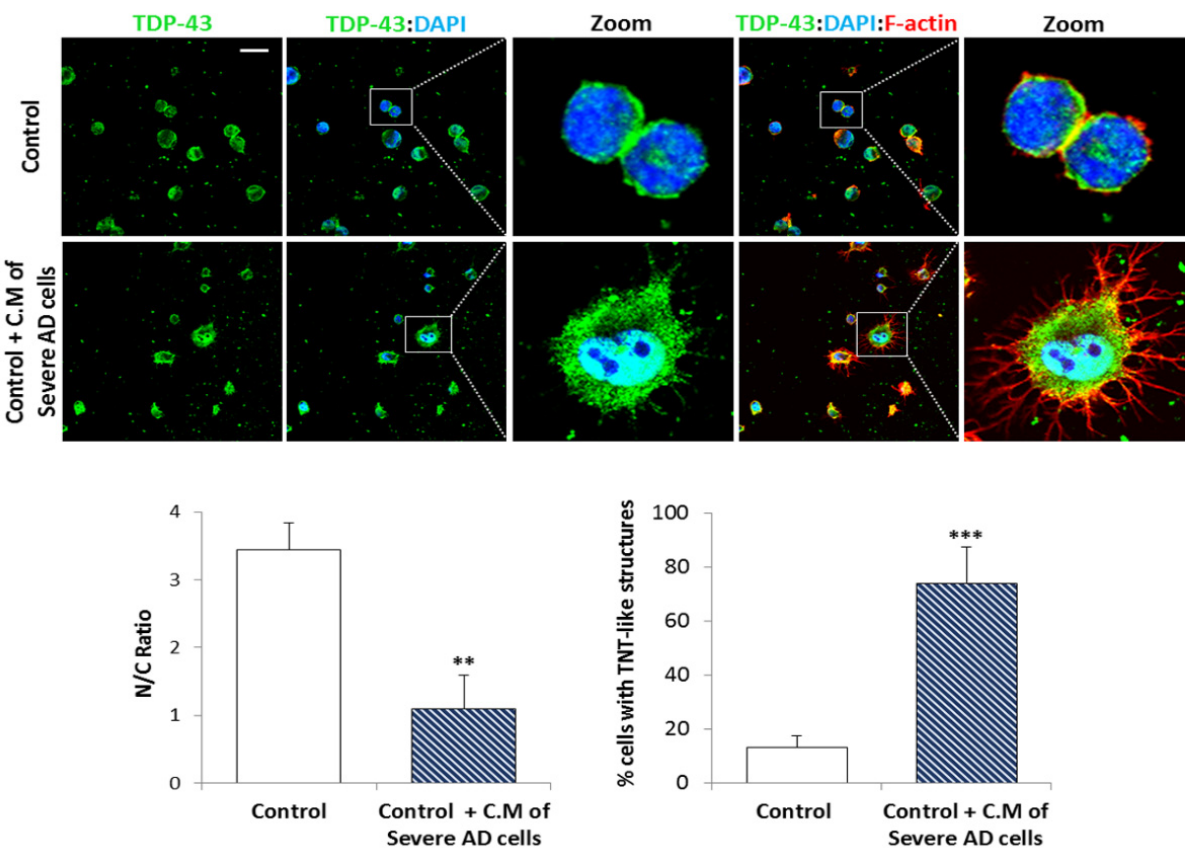

Figure 5. Conditioned medium (CM) of AD lymphoblasts induces TDP-43 pathology in control cells. (A) Immunofluorescence of pTDP-43 (green) and DAPI staining (blue) in control lymphoblasts cultured with $\mathrm{CM}$ of severe $\mathrm{AD}$ cells for $72 \mathrm{~h}$ versus untreated control cells. Fluorescence quantification was performed using Image J software in at least 4 fields of view. (B) Confocal immunofluorescence images of TDP-43 (green), F-actin (red) and DAPI staining (blue) in control lymphoblasts cultured in presence or absence of CM of severe AD cells for $72 \mathrm{~h}$. Nucleo-cytoplasm ratio (mean nuclear intensity divided by the mean cytoplasmic intensity) and \% of cells with F-actin protrusions (TNT-like structures) were measured in at least 4 fields of view using Image J software. (A.U, arbitrary units). Scale bars, $20 \mu \mathrm{m}$. Bars are the mean \pm SD of three independent experiments Statistical analysis was performed using the Student $t$ test. $\left({ }^{*} p<0.05,{ }^{* *} p<0.01\right.$, $\left.{ }^{* * *} p<0.001\right)$.

Furthermore, CM from AD lymphoblasts induces also TDP-43 pathological changes, mislocalization and generation of TDP-43 aggregates in osteosarcoma U2OS cell line (Figure 6). 
A)

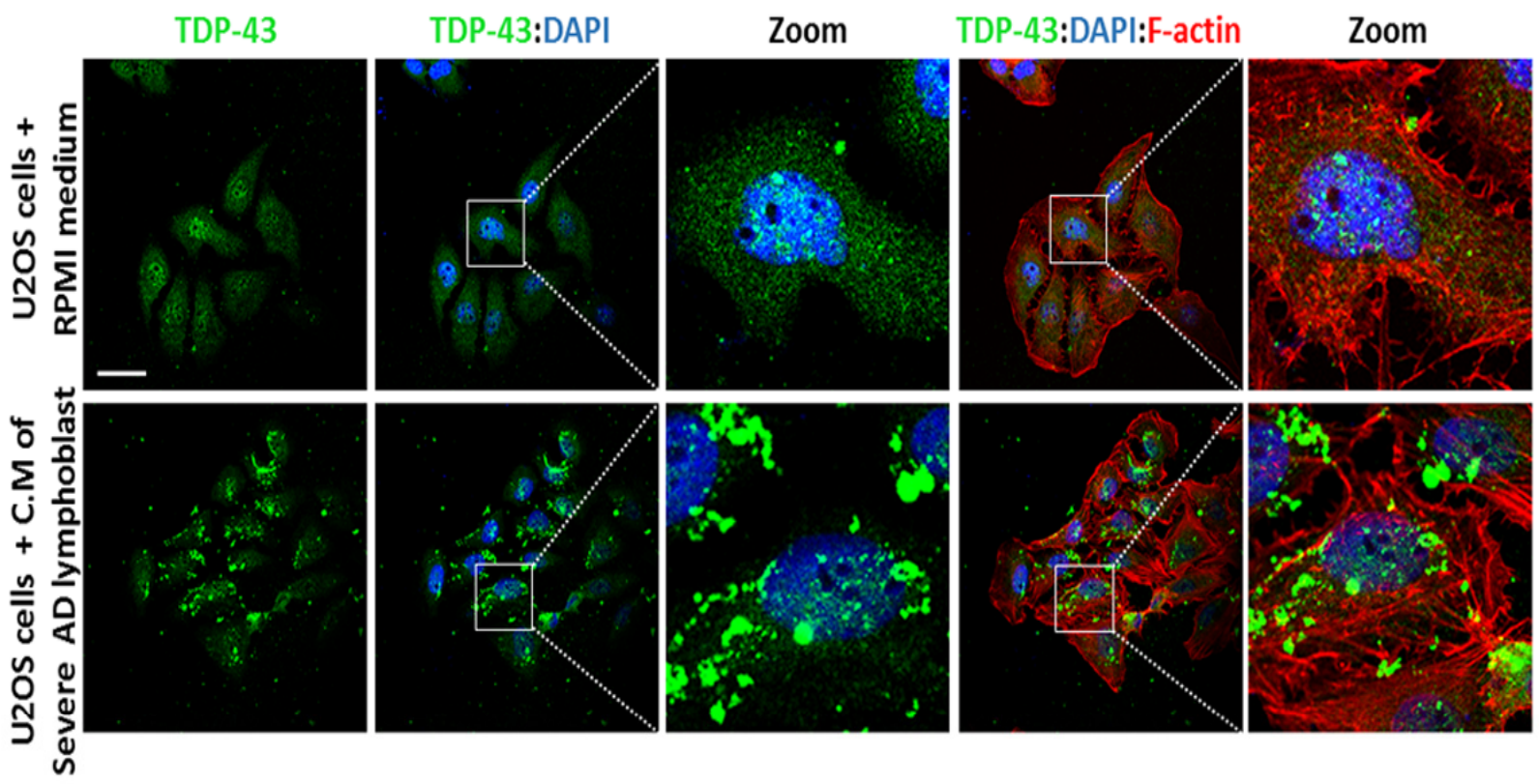

B)

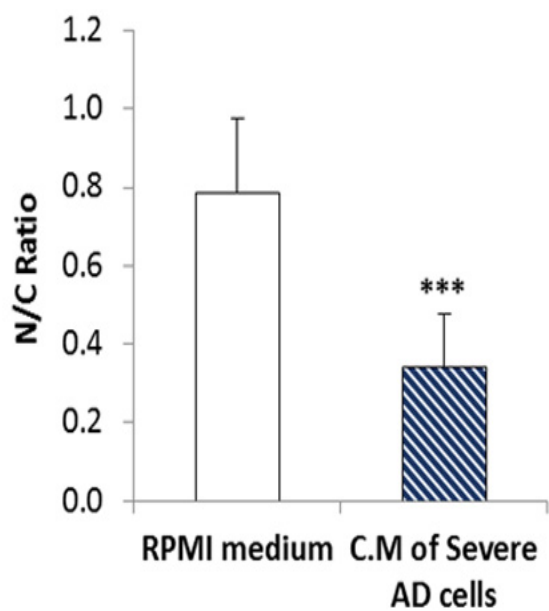

C)

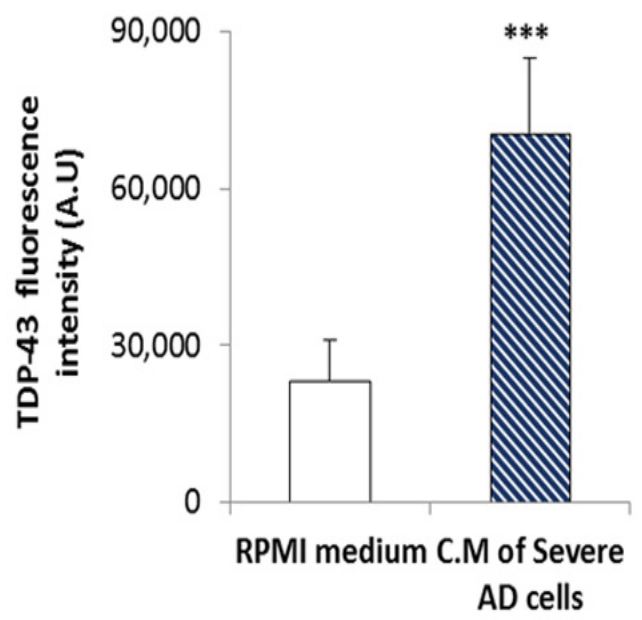

Figure 6. Conditioned medium (CM) of AD lymphoblasts induces TDP-43 pathology in U2OS osteosarcoma cells. (A) Confocal immunofluorescence images of TDP-43 (green), F-actin (red) and DAPI staining (blue) in U2OS cells treated with RPMI medium or CM of severe AD lymphoblasts for $72 \mathrm{~h}$. Scale bar, $40 \mu \mathrm{m}$. (B) Nucleo-cytoplasm ratio (mean nuclear intensity divided by the mean cytoplasmic intensity) and (C) fluorescence intensity was measured cell to cell using Image J software in at least 4 fields of view. (A.U, arbitrary units). Bars are the mean \pm SD of two independent experiments. Statistical analysis was performed using the Student $t$ test. $\left.{ }^{* * *} p<0.001\right)$.

Finally, we isolated extracellular vesicles (EVs) from CM of control and AD cells, and NTA analysis was used to identify their size and concentration. As shown in Figure 7A, there was an apparent increase in particle size mean and concentration in severe AD cases. We then, performed Western blotting to detect the presence of pathological TDP-43 by using an antibody against the C-t epitope of TDP-43 (Proteintech, 67345-1-Ig), and anti-flotillin-1 in cell lysates and EVs from control and AD lymphoblasts (Figure 7B). GAPDH and tubulin antibodies were included as specificity control markers since they are not appreciably 
secreted in EVs. It is shown that the EV fractions isolated from severe AD lymphoblasts were particularly enriched in fragmented TDP-43, as compared to EVs from control cells.

A)
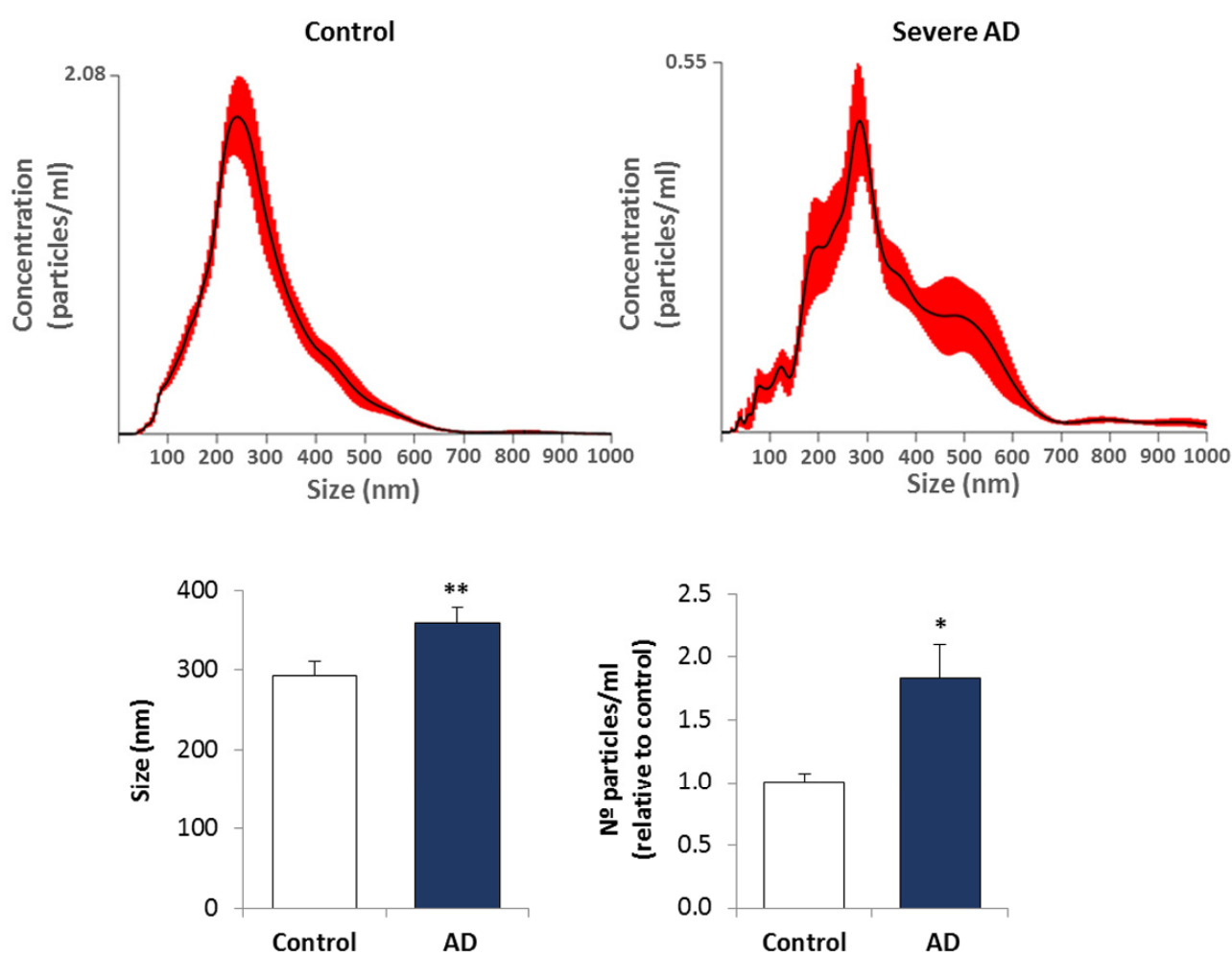

B)

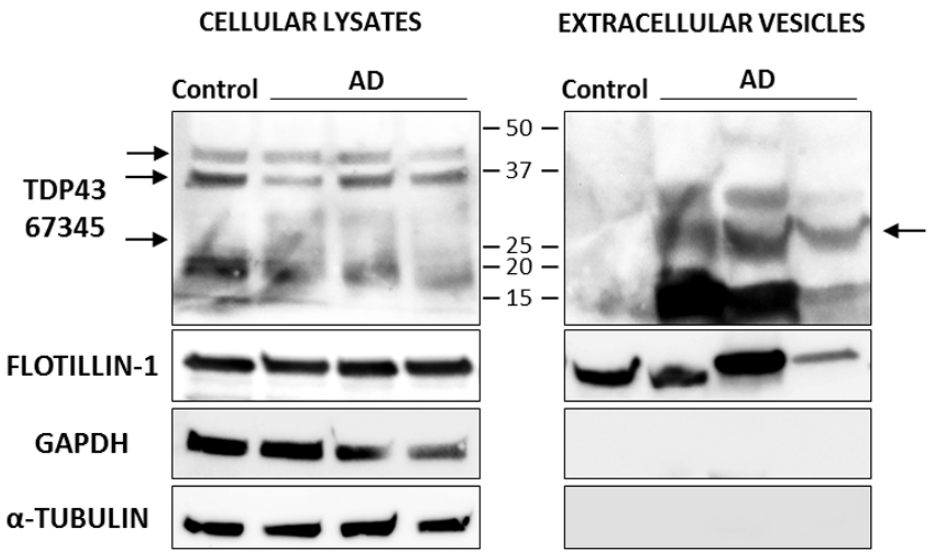

Figure 7. Extracellular Vesicles isolated from AD lymphoblasts showed an increase in size and concentration and were enriched in fragmented TDP-43. (A) Quantification of size and concentration of EVs released from control or severe AD lymphoblasts by NTA. Bars are the mean \pm SD of three independent experiments. Statistical analysis was performed using the Student $t$ test. $\left({ }^{*} p<0.05\right.$, ** $p<0.01$ ) (B) Western blot analysis of C-t TDP-43 in cellular lysates or extracellular vesicles of the indicated samples. $\alpha$-tubulin and GAPDH were used as negative controls for EVs and Flotillin-1 as positive control. The arrow points to the $25 \mathrm{KD}$ TDP43 fragment. 


\section{Discussion}

Over the past decade, TDP-43 deposition has been associated with an increasing number of neurodegenerative diseases [45] being the primary disease pathogenic factor such in the case of ALS, or a relevant protein that increase the pathogenicity present in others diseases. The latter is the case of $\mathrm{AD}$, in where amyloid- $\beta$ and tau pathologies may be exacerbated by the presence of TDP-43 [46,47]. However, the pathophysiological mechanisms through which TDP-43 mediates neurodegeneration appears complex, and deciphering these molecular processes seems critical for the development of effective therapies.

In this study we have examined some TDP-43 features in peripheral cells from AD patients as a function of disease severity. For this purpose, a comparative study on TDP-43 expression levels as well as TDP-43 phosphorylation pattern, protein fragmentation and subcellular localization was performed in lymphoblasts derived from control subjects and mild, moderate and severe AD patients.

The results herein presented show the presence of pathological features of TDP-43 in these easily accessible patient-derived cell lines, that could be considered systemic manifestations of the disease. Increased TDP-43 phosphorylation, protein cleavage, and cytosolic TDP-43 accumulation are more evident in lymphoblasts from severe AD patients. Moreover, higher expression of TDP-43 mRNA was observed in moderate and severe $\mathrm{AD}$ cases, which may be the result of increased self-regulation of TDP-43 expression, in order to maintain homeostasis in late stages of $\mathrm{AD}$ [48]. These observations are in line with previous reports that indicate that patients with abnormal TDP-43 immunohistochemistry show more severe hippocampal atrophy and score worse on the Clinical Dementia Rating Scale Sum of Boxes (CDR-SB), Mini-Mental State Examination (MMSE), and other neuropsychological tests [28].

TDP-43 pathological changes observed in AD lymphoblasts are similar to those found in lymphoblastoid cell lines derived from FTLD-TDP and ALS patients $[39,40]$, despite the fact that distribution of TDP-43 pathology in AD seem to be distinct from other TDP-43 proteinopathies [26]. In AD, pathological TDP-43 is limited to the limbic system of the brain, being the amygdala the most vulnerable area [49]. This anatomical distribution of TDP-43 proteinopathy resembles what it is found in the disease recently named LATE (Limbic-predominant age related-TDP-43 encephalopathy) [20]. AD and LATE are often comorbid in individuals past age 80 years old.

Nowadays, there is an expanding field of research trying to elucidate how TDP-43 pathology may be mechanistically related with $\mathrm{AD}$, especially with the limbic-predominant subtype, in which TDP-43 deposition is more frequent [50]. It is now recognized that TDP-43 deposition increases the risk for developing $\mathrm{AD}$ and influences the clinical features of dementia including cognitive deficits [26]. In addition, the fact that TDP-43 deposits are more abundant in the limbic system suggest a possible role of TDP-43 in the action control and emotion processing impaired in $\mathrm{AD}$ due to atrophy of prefrontal cortex and limbic system [6].

TDP-43 may participate in various pathogenic mechanisms underlying AD, such as amyloid $\beta$ deposition, tau hyperphosphorylation, mitochondrial dysfunction, and neuroinflammation [51]. TDP-43 oligomers had been found to co-localize with tau and A $\beta$ in AD [52] and it was reported that the presence of TDP-43 increases senile plaques load, perturbs amyloid clearance and induces synaptic loss [53,54]. On the other hand, TDP-43 seems to play a role in neurofibrillary tangle development [55]. Moreover, an inverse association between TDP- 43 and tau was observed in post-mortem AD brains, which may the result of negative regulation of tau transcription by TDP-43 [56].

TDP-43 pathological features, such as increased phosphorylation, cleavage, aggregation and cytoplasmic accumulation are believed to impaired neuronal function [33]. It is still a matter of debate whether the clearance of TDP-43 from the nucleus causes a loss of normal TDP-43 functions, that leads to neurodegeneration, or, alternatively, the retention of TDP-43 in cytoplasmic aggregates could induce neurodegeneration through a toxic gain of function [57]. Recently, some protein kinase inhibitors such as CK1, CDC7 and TTBK1 
inhibitors have shown to recover TDP-43 homeostasis in immortalized lymphoblast from ALS and FTLD-TDP $[41,58,59]$. These new drug candidates emerge as potential new therapies for correct the TDP-43 pathology present in AD samples, offering also the possibility to be included in multi-target approaches.

Since TDP-43 protein contains a prion-like domain in its C-terminus, it was hypothesized that TDP-43 toxic species could be transmitted intercellularly [60]. Therefore, we look for the presence of TDP-43 in the extracellular medium. Our results showed that the extracellular medium derived from AD was particularly enriched in a TDP-43 fragment of approximately $25 \mathrm{KDa}$, although full-length TDP-43 is also present. Conditioned medium (CM) from AD cells induced, in control lymphoblasts, an increase in TDP-43 phosphorylation as well as TDP-43 cytoplasmic redistribution. Moreover, CM induced changes in cytoskeleton, promoting the appearance of actin protusions in control cells, similar to those found in severe AD lymphoblasts. These protusions resemble the so-called tunneling nanotubes-like structures (TNTs), reported to play an important role in intercellular spread of prions [61]. Our finding that TDP-43 aggregates were detected inside these structures in AD lymphoblasts suggests that they can participate in dissemination of pathological TDP-43 proteinopathy.

Finally, it is worth highlighting that fragmented TDP-43 $(25 \mathrm{KDa})$ and, in less amount, full-length TDP-43 were detected in EVs isolated from AD lymphoblasts. EVs have been shown to participate in the communication and transfer of cargo among different cell types within the CNS [61], modulating the physiological state of the recipient cells. Thus, a similar mechanism seems to be operative in regulating intercellular communication in non-neuronal cells from $\mathrm{AD}$ patients.

\section{Conclusions}

We confirmed that TDP-43 pathology is present in peripheral cells from AD patients, being exacerbated with disease severity. Thus, protein kinase inhibitors able to modulate TDP-43 emerge as promising agents for AD including those patients in more advanced stages. Furthermore, the addition of these treatments to those able to decrease amyloid$\beta$ may open new hopes for AD therapy. A prion-like disease propagation of TDP-43 pathology via actin protrusions and secretion of fragmented TDP-43 in EVs is in line with the finding that conditioned medium from AD cells provoked TDP-43 phosphorylation and cytoplasmic accumulation in control cells. Although further work is warranted for a better understanding of mechanisms involved in disease dissemination and to elucidate the possible interactions of pathological TDP-43 with other AD-associated molecules, amyloid$\beta$ and tau, for patient stratification and development of novel therapeutic strategies, this last discovery support TDP-43 potential therapies as disease-modifying agents able to modulate the neurodegeneration.

\section{Limitations and Future Studies}

The results of this study are somehow limited by the scarce number of patients included in the analysis. The patient-sample set should be increased to validate these results. We believe that the analysis of the complex interactions among TDP- 43 , amyloid- $\beta$, and tau may open new areas of therapeutic interest for the treatment of this devastating disease, mainly based in multitarget approaches. Research aiming to study the influence of protein kinase inhibitors able to recover TDP- 43 homeostasis, in pathogenic mechanisms underlying $\mathrm{AD}$ pathology and spreading is ongoing in our laboratory. 
Author Contributions: Conceptualization, A.M. and Á.M.-R.; Investigation, E.P.C. and A.R.-F.; Resources, Á.M.-R., A.M. and V.P.; Methodology, E.P.C. and V.P.; Writing Original Draft Preparation Á.M.-R. and A.M.; Writing—review \& editing E.P.C., V.P., Á.M.-R. and A.M.; E.P.C. prepared the Figures; Funding Acquisition, A.M., Á.M.-R. and V.P. All authors have read and agreed to the published version of the manuscript.

Funding: This work has been funded by AEI (grants PID2019-105600RB-I00 to AM, and grant RTI2018-096100-B-I00 to A.M-R); CM (grant B2017/BMD-3813) and ISCiii (grant CB18/05/00040, CIBERNED) and La Caixa grant LCF/BQ/PR18/11640007 to VP.

Institutional Review Board Statement: The study was conducted according to the guidelines of the Declaration of Helsinki and approved by the Institutional Review Board of Hospital Doce de Octubre (Madrid, Spain) and the Ethics Committee of the Spanish Council of Higher Research.

Informed Consent Statement: Informed consent was obtained from all subjects involved in this study.

Data Availability Statement: The datasets analyzed during the present study are available from the corresponding authors on reasonable request.

Acknowledgments: We would like to thank to all patients, their families and clinicians involved in this study We are very thankful to Manuel Izquierdo from Instituto de Investigaciones Biomédicas Alberto Sols for his technical advice on extracellular vesicle measurements and providing access to NTA technology for this work.

Conflicts of Interest: All the authors declare no competing interests.

\section{References}

1. Breijyeh, Z.; Karaman, R. Comprehensive review on Alzheimer's disease: Causes and treatment. Molecules 2020, $25,5789$. [CrossRef] [PubMed]

2. Hou, Y.; Dan, X.; Babbar, M.; Wei, Y.; Hasselbalch, S.G.; Croteau, D.L.; Bohr, V.A. Ageing as a risk factor for neurodegenerative disease. Nat. Rev. Neurol. 2019, 15, 565-581. [CrossRef] [PubMed]

3. Qiu, C.; Kivipelto, M.; von Strauss, E. Epidemiology of Alzheimer's disease: Occurrence, determinants, and strategies toward intervention. Dialogues Clin. Neurosci. 2009, 11, 111-128. [CrossRef] [PubMed]

4. Prince, M.; Bryce, R.; Albanese, E.; Wimo, A.; Ribeiro, W.; Ferri, C.P. The global prevalence of dementia: A systematic review and metaanalysis. Alzheimers Dement. 2013, 9, 63-75. [CrossRef] [PubMed]

5. Deture, M.A.; Dickson, D.W. The neuropathological diagnosis of Alzheimer's disease. Mol. Neurodegener. 2019, 14, 32. [CrossRef]

6. Battaglia, S.; Serio, G.; Scarpazza, C.; D'Ausilio, A.; Borgomaneri, S. Frozen in (e)motion: How reactive motor inhibition is influenced by the emotional content of stimuli in healthy and psychiatric populations. Behav. Res. Ther. 2021, 146, 103963. [CrossRef]

7. $\quad$ Bekris, L.M.; Yu, C.-E.; Bird, T.D.; Tsuang, D.W. Genetics of Alzheimer disease. J. Geriatr. Psychiatry Neurol. 2010, 23, 213-227. [CrossRef]

8. Van Cauwenberghe, C.; van Broeckhoven, C.; Sleegers, K. The genetic landscape of Alzheimer disease: Clinical implications and perspectives. Genet. Med. 2016, 18, 421-430. [CrossRef]

9. Hannon, E.; Shireby, G.L.; Brookes, K.; Attems, J.; Sims, R.; Cairns, N.J.; Love, S.; Thomas, A.J.; Morgan, K.; Francis, P.T.; et al. Genetic risk for Alzheimer's disease influences neuropathology via multiple biological pathways. Brain Commun. 2020, 2 , fcaa167. [CrossRef]

10. Carreiras, M.C.; Mendes, E.; Perry, M.J.; Francisco, A.P.; Marco-Contelles, J. The multifactorial nature of Alzheimer's disease for developing potential therapeutics. Curr. Top. Med. Chem. 2013, 13, 1745-1770. [CrossRef]

11. Lloret, A.; Monllor, P.; Esteve, D.; Cervera-Ferri, A.; Lloret, M.-A. Obesity as a risk factor for Alzheimer's disease: Implication of leptin and glutamate. Front. Neurosci. 2019, 13, 508. [CrossRef] [PubMed]

12. Lee, H.J.; Seo, H.I.; Cha, H.Y.; Yang, Y.J.; Kwon, S.H.; Yang, S.J. Diabetes and Alzheimer's disease: Mechanisms and nutritional aspects. Clin. Nutr. Res. 2018, 7, 229. [CrossRef] [PubMed]

13. Nguyen, T.T.; Ta, Q.T.H.; Nguyen, T.K.O.; Nguyen, T.T.D.; van Giau, V. Type 3 diabetes and its role implications in Alzheimer's disease. Int. J. Mol. Sci. 2020, 21, 3165. [CrossRef] [PubMed]

14. Yanker, B.A. New clues to Alzheimer's disease: Unraveling the roles of amyloid and tau. Nat. Med. 1996, 2, 850-852. [CrossRef]

15. Selkoe, D.J. Alzheimer's disease results from the cerebral accumulation and cytotoxicity of amyloid beta-protein. J. Alzheimer's Dis. 2001, 3, 75-80. [CrossRef]

16. Jellinger, K.A. Alzheimer 100-Highlights in the history of Alzheimer research. J. Neural Transm. 2006, 113, 1603-1623. [CrossRef]

17. Jellinger, K.A. Neuropathological subtypes of Alzheimer's disease. Acta Neuropathol. 2012, 123, 153-154. [CrossRef]

18. Amador-Ortiz, C.; Lin, W.L.; Ahmed, Z.; Personett, D.; Davies, P.; Duara, R.; Graff-Radford, N.R.; Hutton, M.L.; Dickson, D.W. TDP-43 immunoreactivity in hippocampal sclerosis and Alzheimer's disease. Ann. Neurol. 2007, 61, 435-445. [CrossRef] 
19. Arai, T.; Mackenzie, I.R.A.; Hasegawa, M.; Nonoka, T.; Niizato, K.; Tsuchiya, K.; Iritani, S.; Onaya, M.; Akiyama, H. Phosphorylated TDP-43 in Alzheimer's disease and dementia with lewy bodies. Acta Neuropathol. 2009, 117, 125-136. [CrossRef]

20. Nelson, P.T.; Dickson, D.W.; Trojanowski, J.Q.; Jack, C.R.; Boyle, P.A.; Arfanakis, K.; Rademakers, R.; Alafuzoff, I.; Attems, J.; Brayne, C.; et al. Limbic-predominant age-related TDP-43 encephalopathy (LATE): Consensus working group report. Brain 2019, 142, 1503-1527. [CrossRef]

21. Mackenzie, I.R.A.; Rademakers, R. The role of transactive response DNA-binding protein-43 in amyotrophic lateral sclerosis and frontotemporal dementia. Curr. Opin. Neurol. 2008, 21, 693-700. [CrossRef] [PubMed]

22. Devenney, E.; Vucic, S.; Hodges, J.R.; Kiernan, M.C. Motor neuron disease-frontotemporal dementia: A clinical continuum. Expert Rev. Neurother. 2015, 15, 509-522. [CrossRef] [PubMed]

23. Burrell, J.R.; Halliday, G.M.; Kril, J.J.; Ittner, L.M.; Götz, J.; Kiernan, M.C.; Hodges, J.R. The frontotemporal dementia-motor neuron disease continuum. Lancet 2016, 388, 919-931. [CrossRef]

24. Hodges, J.R.; Davies, R.R.; Xuereb, J.H.; Casey, B.; Broe, M.; Bak, T.H.; Kril, J.J.; Halliday, G.M. Clinicopathological correlates in frontotemporal dementia. Ann. Neurol. 2004, 56, 399-406. [CrossRef]

25. Brooks, B.R.; Miller, R.G.; Swash, M.; Munsat, T.L. El Escorial revisited: Revised criteria for the diagnosis of amyotrophic lateral sclerosis. Amyotroph. Lateral Scler. Other Mot. Neuron Disord. 2000, 1, 293-299. [CrossRef] [PubMed]

26. Meneses, A.; Koga, S.; O'Leary, J.; Dickson, D.W.; Bu, G.; Zhao, N. TDP-43 pathology in Alzheimer's disease. Mol. Neurodegener. 2021, 16, 84. [CrossRef] [PubMed]

27. Tomé, S.O.; Vandenberghe, R.; Ospitalieri, S.; van Schoor, E.; Tousseyn, T.; Otto, M.; von Arnim, C.A.F.; Thal, D.R. Distinct molecular patterns of TDP-43 pathology in Alzheimer's disease: Relationship with clinical phenotypes. Acta Neuropathol. Commun. 2020, 8, 61. [CrossRef]

28. Josephs, K.A.; Whitwell, J.L.; Knopman, D.S.; Hu, W.T.; Stroh, D.A.; Baker, M.; Rademakers, R.; Boeve, B.F.; Parisi, J.E.; Smith, G.E.; et al. Abnormal TDP-43 immunoreactivity in AD modifies clinicopathologic and radiologic phenotype. Neurology 2008, 70, 1850-1857. [CrossRef]

29. Tremblay, C.; St-Amour, I.; Schneider, J.; Bennett, D.A.; Calon, F. Accumulation of transactive response DNA binding protein 43 in mild cognitive impairment and Alzheimer disease. J. Neuropathol. Exp. Neurol. 2011, 70, 788-798. [CrossRef]

30. Wilson, R.S.; Yu, L.; Trojanowski, J.Q.; Chen, E.-Y.; Boyle, P.A.; Bennett, D.A.; Schneider, J.A. TDP-43 pathology, cognitive decline, and dementia in old age. JAMA Neurol. 2013, 70, 1418. [CrossRef]

31. Warraich, S.T.; Yang, S.; Nicholson, G.A.; Blair, I.P. TDP-43: A DNA and RNA binding protein with roles in neurodegenerative diseases. Int. J. Biochem. Cell Biol. 2010, 42, 1606-1609. [CrossRef] [PubMed]

32. Ratti, A.; Buratti, E. Physiological functions and pathobiology of TDP-43 and FUS/TLS proteins. J. Neurochem. 2016, 138 (Suppl. 1), 95-111. [CrossRef] [PubMed]

33. Palomo, V.; Tosat-Bitrian, C.; Nozal, V.; Nagaraj, S.; Martin-Requero, A.; Martinez, A. TDP-43: A key therapeutic target beyond amyotrophic lateral sclerosis. ACS Chem. Neurosci. 2019, 10, 1183-1196. [CrossRef] [PubMed]

34. Neumann, M.; Sampathu, D.M.; Kwong, L.K.; Truax, A.C.; Micsenyi, M.C.; Chou, T.T.; Bruce, J.; Schuck, T.; Grossman, M.; Clark, C.M.; et al. Ubiquitinated TDP-43 in frontotemporal lobar degeneration and amyotrophic lateral sclerosis. Science 2008, 314, 130-133. [CrossRef] [PubMed]

35. Nonaka, T.; Kametani, F.; Arai, T.; Akiyama, H.; Hasegawa, M. Truncation and pathogenic mutations facilitate the formation of intracellular aggregates of TDP-43. Hum. Mol. Genet. 2009, 18, 3353-3364. [CrossRef] [PubMed]

36. Bartolomé, F.; de Las Cuevas, N.; Muñoz, Ú.; Bermejo, F.; Martín-Requero, Á. Impaired apoptosis in lymphoblasts from Alzheimer's disease patients: Cross-talk of $\mathrm{Ca}^{+} /$Calmodulin and ERK1/2 signaling pathways. Cell. Mol. Life Sci. 2007, 64, 1437-1448. [CrossRef] [PubMed]

37. Muñoz, U.; Bartolomé, F.; Bermejo, F.; Martín-Requero, A. Enhanced proteasome-dependent degradation of the CDK inhibitor P27kip1 in immortalized lymphocytes from Alzheimer's dementia patients. Neurobiol. Aging 2008, 29, 1474-1484. [CrossRef]

38. Esteras, N.; Alquézar, C.; de la Encarnación, A.; Martín-Requero, Á. Lymphocytes in Alzheimer's disease pathology: Altered signaling pathways. Curr. Alzheimer Res. 2016, 13, 439-449. [CrossRef]

39. Alquezar, C.; Salado, I.G.; de La Encarnación, A.; Pérez, D.I.; Moreno, F.; Gil, C.; de Munain, A.L.; Martínez, A.; Martín-Requero, Á. Targeting TDP-43 phosphorylation by casein kinase-1 $\delta$ inhibitors: A novel strategy for the treatment of frontotemporal dementia. Mol. Neurodegener. 2016, 11, 36. [CrossRef]

40. Posa, D.; Martínez-González, L.; Bartolomé, F.; Nagaraj, S.; Porras, G.; Martínez, A.; Martín-Requero, Á. Recapitulation of pathological TDP-43 features in immortalized lymphocytes from sporadic ALS patients. Mol. Neurobiol. 2018, 56, 2424-2432. [CrossRef]

41. Vaca, G.; Martinez-Gonzalez, L.; Fernandez, A.; Rojas-Prats, E.; Porras, G.; Cuevas, E.P.; Gil, C.; Martinez, A.; Martin-Requero, Á. Therapeutic potential of novel cell division cycle kinase 7 inhibitors on TDP-43-related pathogenesis such as frontotemporal lobar degeneration (FTLD) and amyotrophic lateral sclerosis (ALS). J. Neurochem. 2021, 156, 379-390. [CrossRef] [PubMed]

42. McKhann, G.; Drachman, D.; Folstein, M.; Katzman, R.; Price, D.; Stadlan, E.M. Clinical diagnosis of Alzheimer's disease: Report of the NINCDS-ADRDA work group under the auspices of department of health and human services task force on Alzheimer's disease. Neurology 1984, 34, 939-944. [CrossRef] [PubMed]

43. Folstein, M.F.; Folstein, S.E.; Mchugh, P.R. "Mini-mental State" a practical method for grading the cognitive state of patients for the clinician. J. Psychiatr. Res. 1975, 12, 189-193. [CrossRef] 
44. Hussain, T.; Mulherkar, R. Lymphoblastoid cell lines: A continuous in vitro source of cells to study carcinogen sensitivity and DNA repair. Int. J. Mol. Cell. Med. 2012, 1,75-87.

45. De Boer, E.M.J.; Orie, V.K.; Williams, T.; Baker, M.R.; de Oliveira, H.M.; Polvikoski, T.; Silsby, M.; Menon, P.; van den Bos, M.; Halliday, G.M.; et al. TDP-43 proteinopathies: A new wave of neurodegenerative diseases. J. Neurol. Neurosurg. Psychiatry 2021, 92, 86-95. [CrossRef]

46. Chornenkyy, Y.; Fardo, D.W.; Nelson, P.T. Tau and TDP-43 proteinopathies: Kindred pathologic cascades and genetic pleiotropy. Lab. Investig. 2019, 99, 993-1007. [CrossRef]

47. Shih, Y.-H.; Tu, L.-H.; Chang, T.-Y.; Ganesan, K.; Chang, W.-W.; Chang, P.-S.; Fang, Y.-S.; Lin, Y.-T.; Jin, L.-W.; Chen, Y.-R. TDP-43 interacts with amyloid- $\beta$, inhibits fibrillization, and worsens pathology in a model of Alzheimer's disease. Nat. Commun. 2020, 11, 5950. [CrossRef]

48. Avendaño-Vázquez, S.E.; Dhir, A.; Bembich, S.; Buratti, E.; Proudfoot, N.; Baralle, F.E. Autoregulation of TDP-43 MRNA levels involves interplay between transcription, splicing, and alternative polyA site selection. Genes Dev. 2012, 26, 1679-1684. [CrossRef]

49. Uryu, K.; Nakashima-Yasuda, H.; Forman, M.S.; Kwong, L.K.; Clark, C.M.; Grossman, M.; Miller, B.L.; Kretzschmar, H.A.; Lee, V.M.Y.; Trojanowski, J.Q.; et al. Concomitant TAR-DNA-binding protein 43 pathology is present in Alzheimer disease and corticobasal degeneration but not in other tauopathies. J. Neuropathol. Exp. Neurol. 2008, 67, 555-564. [CrossRef]

50. Josephs, K.A.; Whitwell, J.L.; Tosakulwong, N.; Weigand, S.D.; Murray, M.E.; Liesinger, A.M.; Petrucelli, L.; Senjem, M.L.; Ivnik, R.J.; Parisi, J.E.; et al. TAR DNA-binding protein 43 and pathological subtype of Alzheimer's disease impact clinical features. Ann. Neurol. 2015, 78, 697-709. [CrossRef]

51. Huang, W.; Zhou, Y.; Tu, L.; Ba, Z.; Huang, J.; Huang, N.; Luo, Y. TDP-43: From Alzheimer's disease to limbic-predominant age-related TDP-43 encephalopathy. Front. Mol. Neurosci. 2020, 13, 26. [CrossRef] [PubMed]

52. Montalbano, M.; McAllen, S.; Cascio, F.L.; Sengupta, U.; Garcia, S.; Bhatt, N.; Ellsworth, A.; Heidelman, E.A.; Johnson, O.D.; Doskocil, S.; et al. TDP-43 and tau oligomers in Alzheimer's disease, amyotrophic lateral sclerosis, and frontotemporal dementia. Neurobiol. Dis. 2020, 146, 105130. [CrossRef] [PubMed]

53. Herman, A.M.; Khandelwal, P.J.; Stanczyk, B.B.; Rebeck, G.W.; Moussa, C.E.-H. $\beta$-amyloid triggers ALS-associated TDP-43 pathology in AD models. Brain Res. 2011, 1386, 191-199. [CrossRef] [PubMed]

54. Paolicelli, R.C.; Jawaid, A.; Henstridge, C.M.; Valeri, A.; Merlini, M.; Robinson, J.L.; Lee, E.B.; Rose, J.; Appel, S.; Lee, V.M.-Y.; et al. TDP-43 depletion in microglia promotes amyloid clearance but also induces synapse loss. Neuron 2017, 95, 297-308.e6. [CrossRef] [PubMed]

55. Davis, S.A.; Gan, K.A.; Dowell, J.A.; Cairns, N.J.; Gitcho, M.A. TDP-43 expression influences amyloid $\beta$ plaque deposition and tau aggregation. Neurobiol. Dis. 2017, 103, 154-162. [CrossRef]

56. Gu, J.; Wu, F.; Xu, W.; Shi, J.; Hu, W.; Jin, N.; Qian, W.; Wang, X.; Iqbal, K.; Gong, C.-X.; et al. TDP-43 suppresses tau expression via promoting its MRNA instability. Nucleic Acids Res. 2017, 45, 6177-6193. [CrossRef]

57. Lee, E.B.; Lee, V.M.-Y.; Trojanowski, J.Q. Gains or losses: Molecular mechanisms of TDP43-mediated neurodegeneration. Nat. Rev. Neurosci. 2011, 13, 38-50. [CrossRef]

58. Martínez-González, L.; Rodríguez-Cueto, C.; Cabezudo, D.; Bartolomé, F.; Andrés-Benito, P.; Ferrer, I.; Gil, C.; Martín-Requero, Á.; Fernández-Ruiz, J.; Martínez, A.; et al. Motor neuron preservation and decrease of in vivo TDP-43 phosphorylation by protein

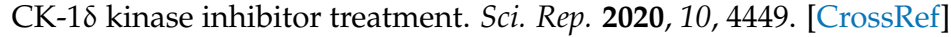

59. Nozal, V.; Martínez-González, L.; Gomez-Almeria, M.; Gonzalo-Consuegra, C.; Santana, P.; Chaikuad, A.; Pérez-Cuevas, E.; Knapp, S.; Lietha, D.; Ramírez, D.; et al. TDP-43 modulation by tau-tubulin kinase 1 inhibitors: A new avenue for future amyotrophic lateral sclerosis therapy. J. Med. Chem. 2022, 65, 1585-1607. [CrossRef]

60. Budini, M.; Romano, V.; Quadri, Z.; Buratti, E.; Baralle, F.E. TDP-43 loss of cellular function through aggregation requires additional structural determinants beyond its C-terminal Q/N prion-like domain. Hum. Mol. Genet. 2015, 24, 9-20. [CrossRef]

61. Gousset, K.; Schiff, E.; Langevin, C.; Marijanovic, Z.; Caputo, A.; Browman, D.T.; Chenouard, N.; de Chaumont, F.; Martino, A.; Enninga, J.; et al. Prions hijack tunnelling nanotubes for intercellular spread. Nat. Cell Biol. 2009, 11, 328-336. [CrossRef] [PubMed] 